\title{
Thought on Smart City Construction Planning Based on System Engineering
}

\author{
Shen Xilin ${ }^{1, a}$, Zhang Qinlan ${ }^{2, b}$ \\ ${ }^{1}$ Department of Economics and Management, Southwest Petroleum University, Chengdu, \\ R.P.China \\ ${ }^{2}$ Department of Economics and Management, Southwest Petroleum University, Chengdu, \\ R.P.China \\ ashenxilin@vip.sina.com, ${ }^{b} 597892306 @ q q . c o m$
}

Key words: System engineering, smart city, construction plan.

\begin{abstract}
Smart city comes up as a result of the new technology innovation. As a new field leading to era change, its theory and practice has been still under way. From the historical experience of city construction, the height a city planning could reach is the level the city construction can reach, thus, a high-quality construction plan characterized with wholeness, insights and systematicness is needed. In this paper, smart city was researched as a system engineering in a manner of systematic analysis and reasonable thinking, to study the theoretical base and technological requirements for smart city construction (SCC), and to explore its construction frame, and to propose the 3-D structure of its construction, further to enrich SCC theory and provide an intelligent tank and a scientific basis for its sustainable development.
\end{abstract}

\section{Introduction}

In 2000, Singapore raised the concept of Intelligent City, which was based on modern information technologies, such as artificial intelligence, intelligent control software, expert decision-making system technology and sensing equipments, to enable all kinds of city functions to work intelligently via intelligent information network to share information, resources and tasks. In 2009, IBM brought up the concept of Smart City, which was based on information technologies to balance all kinds of city information systems, to integrate and to coordinate them. In fact, the cognition of Smart City is a gradual process, which is usually closely connected with such technologies as Wifi, internet of things, cloud computing, informationalization, digitalization, intelligence, and perceptualization, based on technologies above to integrate such things as physical facilities, social organizations, and information resources into an organic unity, and to offer a city spirit. Therefore, from the standpoint of some foreign scholars, Smart city was to adopt various advanced technologies especially information technologies to improve a city status, to plan a city based on the theory of intelligence, to construct and organize a city intelligently, further to prompt the accessibility and convenience of a city space, to make the city more vigorous. In general, Smart city is based on such modern technologies as internet, wifi, internet of things, image acquisition technology, smart sensing technology, a large-scale server, and cloud computing, etc., to construct a net platform of city information organization and comprehensive decision-making, to systematically integrate hard and soft resources of the city, to realize the perceptualization, digitalization, mutual connection, intelligization, and human orientation, just like a nerve system to a city which can make the city alive, to realize a prosperous, harmonious and happy city.

\section{Background of Smart city construction (SCC)}

Harmonious Cities: State of World's Cities 2008/2009 issued by UN pointed out: over a half population live in cities, such change has not yet finished, in the following 4 decades, such figure will soar dramatically, the percentage of people living in cities will reach $70 \%$ by 2050 . During global urbanization, the speed in Asia is rather fast, while China plays a leading role, it's estimated 
that by 2050, more than 70\% people will live in cities, by then the level of urbanization in Asia will leave Africa far behind. With the city expansion at a rapid rate in China, there have been a series of problems urgent to be solved, such as poor air quality, traffic congestion, dense population, lack of educational and health care resources, and a practical feasible solution to such problems is smart city, whose construction will play an unmatched role in social advancement, economic development and improvement on human living standard.

1 Direct drive form information technology development

In today's society characterized with a rapid development of information technology, such technologies as informationalization, digitalization, intelligentization, and human-orientation have changed our way of life at a shocking speed, people have sensed the unprecedented convenience in house environment, work environment, transportation, and life mode, time is shortening, life is speeding up, the world is turning small, communication is increasing, and the way of life is changing in an unnoticeable way, thus with the direct drive from information technology development, SCC is inevitable and irreversible[1].

2 Essential demand from socio-economic development

In China today, urbanization is the major drive for socio-economic development, however, if the urbanization is promoted with a large amount of consumption of fossil energy, minerals, and ecological resources characterized with high-investment, high-consumption and high-emission, such urbanization is not scientific and not sustainable. Therefore, during the process of socio-economic development, a great attention should be paid to the increase in quantity as well as that in quality, to completely transfer the traditional mode of socio-economic development. The proposal of smart city met the essential demand from socio-economic development, based on the purpose of saving resources, intelligent development, fastness and convenience, and sustainable development, which promotes intelligent production, intelligent consumption, intelligent work and intelligent management, in order to solve such problems as economic stagnation, traffic congestion, blocked information, work boredom, and dull life, which is an important revolution in socio-economic field.

3 The inevitable choice for city development

The role SCC plays in city social development and the improvement in people's living standard has gained universal cognition both at home and abroad. According to the process of city development, during the process from the agricultural age of slash-and-burn cultivation to the information age with advanced technologies, the city has experienced industrialization and electrification, while the appearance of smart city will be another promotion of city level, which is the inevitable choice for city development. Intelligentization is to use modern scientific technologies to merge human society with the physical world, to connect the virtual world with the real world, to optimize the mode of city operation and the way of social organization, and to prompt the transfer of way of life and the improvement in life quality.

\section{Status quo of SCC}

Since the proposal of smart city, it has gained a universal concern all over the world, in the present, a lot of cities in the world have proposed or begun to implement Smart City Strategy, almost every country has raised the special prospect of smart city development, thus SCC comes to the phrase of rapid development.

1 Status quo of SCC abroad

Almost every government in the world has raised a blueprint for future city development based on modern information technology in the last several years.

In Europe, in 2007, EU put forward a set of goals of SCC and put them into practice, the evaluation standard of a smart city established by EU including intelligent economy, intelligent mobility, intelligent environment, intelligent treatment and etc. EU planned to support such key fields as internet, cloud computing and internet of things, to tackle technological problems, and made A Strategic Road Map of Internet of Things.

In US, in September, 2009, Dubuque, a city in Iowa in midwest, and IBM jointly announced that 
they would construct the first smart city in US, with a series of new technologies from IBM to be used in Dubuque, to fully digitalize Dubuque, and to connect all the resources (water, electricity, oil, gas, transportation, and public service, etc.), through monitoring, analyzing and integrating various data, and an intelligent response afterwards would be made to serve the local citizen[2].

In Japan, in July, 2009, the headquarters of IT strategy in Japan made i-Japan 2015 Strategy, aiming at integrating digital information technology into all parts of life and production, focusing on intelligent transportation, logistics system, e-government, medical care, education and intellectual training, etc.

2 Status quo at home

SCC has become a new development direction for cities in China. On $2^{\text {nd }}$ November, 2010, "2010 China Smart City Forum” which had receive considerable concern was held in Wuhan, China, which has been a trademark in the history of smart city development in China ${ }^{[2]}$. In 2010, over 20 cities in China made a smart city plan, among which over 10 cities including Beijing, Shanghai, Shenzhen, Nanjing, Guangzhou, Wuhan had included smart city into the "Twelfth-Five-Year Plan" and began to carry it out. On Jan. 29 ${ }^{\text {th }}, 2013$, Ministry of Housing and Urban-Rural Development of the People's Republic of China (MOHURD) issued the first 90 pilot smart cities, covering 37 prefecture-level cities, 50 counties (districts), and 3 townships. In the last 3 years of late Twelfth-Five Year Plan, China Development Bank and MOHURD cooperated to invest 80 billion Yuan into SCC. On August 5 ${ }^{\text {th }}, 2013$, a list of another 103 pilot smart cities was issued by MOHURD.

Smart Shanghai: in Shanghai, SCC is aiming at 8 special projects for enterprises covering cloud computing, internet of things, TD-LTE, advanced software, integrated circuit, next generation network, IOV, and information service, and at 4 major programs including smart portal, smart administration, smart health care, three networks convergence and innovation.

Smart Shenzhen: on May $8^{\text {th }}, 2012$, Guideline of Smart Shenzhen was issued, in which a new mode of people's living and production was described. Advanced information infrastructure and digitalized 3-D city modeling technology were adopted in Shenzhen to improve the development environment of a smart city, and to form a new mode of city living, industrial development and social administration based on a large mount of information and intelligent filtering and processing, enable the life and production to be more electrified, intelligent and convenient[3].

Smart Yangzhou: in Yangzhou, SCC was planned to be integrated with the construction of humanism, ecology, fineness and a livable city, in the downtown with an area of almost $100 \mathrm{~km}^{2}$, wifi was planned to cover all the parts, an all-round platform for administration network and information exchange, with the citizen card for multiple use issued to promote a digital life in the city[4].

\section{Goals and principles for SCC}

Smart city is a pilot practice based on new theories and its guidance, which provide a new way for city development. City intelligentization is a new mode and a new way of city development, and it is the long-term goal and blueprint for city development, which is explored by almost every city.

1 SCC goals

China is still the largest developing country in the world, in the following 50 years, the theme "development, management, work and life" will still be the major contents for socio-economic development and urbanization. Thus, SCC in China should be centered on the goal of "more scientific development, more efficient management, more advanced economy, more harmonious society, happier work and better life".SCC should optimize industrial structure, change the way of city development, develop information industry in a large scale, reduce industrial energy consumption, rationalize city industrial structure, and develop stabler[4].

More efficient management: the high-efficient operation of a city should depend on a perceptual, controllable and high intelligent managerial method. Via such technologies as internet of things and GIS, a real time management and control over natural environment such as lakes, forests, and air, etc., city infrastructures such as road, ground facilities, underground pipelines, flowing materials 
such as automobiles, foods and drugs, etc. can be realized, and management and service for the local people, residents, and mobile people can be committed, to realize smart traffic, smart environment protection, smart emergency, smart infrastructure, smart food and drug administration, and smart administration and service, and to reach a new-stage civilization, namely, low-carbon society, green ecology, and harmony between man and nature. More advanced economy. More harmonious society. Happier work.

Better life: via highly advanced infrastructure and information, citizens can enjoy a cheap and convenient public service integrated with social service, public transportation, health care, and cultural education at any time, any place and through any channel, and as well enjoy a better life with great increase in life quality; at the same, with the strong service capacity, citizens can sense the belonging and recognition, convenience and care, communication and trust, respect and growth. At that time, physical location will not be an obstacle, everyone neighbors another one, companies another one as friends all the time, whether the local residents, or migrant workers will be happy and proud of living and working in such an intelligent and hospital city[5].

2 Principles for SCC

1) Being systematic: basically speaking, smart city is a systematical social engineering, involving the city society as a whole, which is an open complex system, characterized with multi-object, multi-industry, multi-business, multi-levle, and multi-region, thus, a systematic planning is needed for SCC, to deal with city affairs such as administration, economy, culture, education, health care, resources, energy, traffic and environment in a systematic engineering way.

2) Being safe: since smart city is an open system, there is a close communication and cooperation with the external parts, when new-generation information technologies such as internet, internet of things, cloud computing are fully used, at the same time, the safety problems resulted from the influence of modern information technology on SCC should be paid great attention to, to establish a safety guarantee system fitting for SCC, on the context of a full use of internet and the integration of data and resources, the safety of smart city should be ensured to further improve the safety guarantee capacity of the smart city[6].

3) Being stable: SCC in developed countries is the result from IT upgradation. However, in China, there is still a certain difference from developed countries in information infrastructure at present, thus based on the national real situation of low popularity of WAN and deficiency in bandwidth, a step-by-step way should be encouraged, instead of an aimless development at a rather quick speed without a proper goal.

Smart city is a brand new concept, till now, there has not been a globally unified construction mode and way, without mature experience to borrow. SCC in China is still on the preliminary stage, pilot demonstration zones should be continuously practiced to explore a proper construction mode, which can be spread and duplicated based on a full argumentation, to be implemented gradually to promote SCC stably.

4)Being human-orientated: the socio-economic development should be based on the improvement of social welfare of human beings. Thus, SCC should also abide by such principle, to set such affairs as social public service and people's living as the start point of SCC, thus the public can really sense the convenience form IT development regarding life and work, and experience the improvement in life quality and work environment from SCC, leading to the growth in people's happiness index.

During SCC, government should play the leading and dominant role in planning development strategy for SCC, clarifying development goals and major tasks, planning and issuing policies and countermeasures toward the promotion of SCC, strengthening investment guided by government, creating a helpful development environment for SCC, fully exerting the fundamental role of market mechanism in resource allocation, setting the intelligent improvement in advantageous industries and cultivation of new emerging intelligent industries as drive forces, fully enhancing the individual creativity and core competitiveness of intelligent industries, greatly promoting the contribution of intelligent industries to city economic development, and improving the quality and benefit of city economic development[7]. 


\section{The theory and technology foundation of SCC}

\section{Theoretic basis}

SCC is a complex systematic engineering, which originates from the development of systematic ideas, involving the theory of system, theory of control, theory of information, and WSR. Theory of system studies the structure, function and operation rules of the system, and describe it in a mathematic way; theory of control focuses on the control and coordination of the system centered on information and control; theory of information studies the acquisition, transfer, storage, exchange, processing and application of information; WSR is a science dealing with the affairs of physical world, business and human beings.

2 Theory of system

In 1920s, Ludwig Von Bertalanffy, an Austria-American biologist discovered during its study on biology, the more the biology decomposes, the more it loses its whole figure, the less people's understanding and recognition on it is, thus he wrote quite a lot on general system theory, put forward the concept of organic unity in biology, and emphasized the organic unity should be treated and studied as the whole, only through it can the organization theory be found at different levels. In Theoretical Biology published in 1932 and Modern Theories of Development: An Introduction to Theoretical Biology in 1934, he applied coordination, orderliness, and objectiveness into the study of organic unity, followed by three basic concepts, namely, system, dynamics and layer. In General System theory: Foundations, Development, Applications published in 1968, he summarized the concept, methodologies and applications of general system theory, and the core ideas are holism, layer, organic correlation, systematic dynamics, orderliness, and objectivity, which are of great guidance in SCC. Construction planners should be fully aware that smart city system is made up of lots of sub-systems, which are also made up of minor sub-systems, the system unity is based on a certain organizational structure, there is an interaction and interdependence in the inner system between sub-systems and between systems and environment, and there is always an exchange of materials, energy and information between the system and the external environment, the inner structure of the system varies with time change, and the operation of the system is presented with a orderly state[8].

3 Technical basis

Smart city is another leap of city development after industrialization, electrification and digitization, and also a comprehensive use of such modern technologies as internet, Wifi, internet of things, image acquisition, smart sensing, and cloud computing, etc., which have changed people's way of life and work at a dramatic rate.

\section{System model of SCC}

Smart city is a big complex system, SCC plan should involve all kinds of functions of the city in every field from the perspective of system, thus, during its process of planning, the construction idea "from whole to part and from system to branch" should be built.

1 Top design of SCC

Since smart city is a large multi-attributive, multi-level and multi-function system characterized with the integration of data collection, management service and decision making optimization, its top design is of crucial importance. And at the same time, smart city is also a dynamical system with constant development, renewal, and expansion, thus its top design should be characterized with development, compatibility, security and controllability[9].

Its top design involves its general frame, including its general standard system, and a bottom-up inner layer and frame structure. Its standard qualification and its security system will go through the whole system during its planning, each layer and specific project in the system should be done under its guidance and qualification. Its inner up-bottom frame structure includes such layers as the perceptual layer served as the basic environment of intelligence, the communication layer as an important infrastructure, data layer as strategic resources, and application layer to realize the functions of the smart city. In its top design, the basic construction contents should be planned 
generally, mainly including infrastructure, environment management, public management, city security, industrial construction and culture construction.

2 Platform for information management and control over a smart city

The platform for information management and control in a smart city is its brain. Smart city integrates the most advanced IT, whose information level is much higher than previous city construction. At a macro level, its planning should focus on the study, development and use of such aspects of basic city data as its volume, security, renewability, and intelligentization[10]. Information management and control should cover every field in the city as much as possible, to guarantee that smart city can benefit the people's living standard, save energy and resources, and promote scientific, sustainable development of the city.

3 3-D structure of SCC

Based on the general planning of the smart city from the standpoint of system, a 3-D structure of SCC can be figured out, which involves object dimension, business dimension and function dimension. 1) object dimension: it includes public, enterprises, public institutions, governments, etc. 2) business dimension: it includes smart population management, smart government administration, smart financial administration, smart traffic management, smart tourism management, smart education management, smart health care management, smart culture management, smart people's livelihood management, smart community management, smart family management, smart production management, smart market management, smart security management, smart environment management, etc. 3) function dimension: it involves the resources integration (supported by internet, wireless network, and internet of things), information acquisition, information transmission, information process and information use, etc.

\section{Summary}

SCC in China is a strong drive force to handle with "curse of growth retardation" and to overcome "mid-income trap", and also a inevitable choice of socio-economic development on the context of "new normal". To promote SCC is beneficial for optimizing resources allocation, promoting economic development and social advancement, improving ecological quality, and strengthening city competitiveness. However, SCC cann't be accomplished in one move, it is a long-term complex and difficult system engineering, which should be developed steadily and gradually with plans. China should grasp such opportunities to welcome the spring of SCC, to realize the goal of "more scientific development, more efficient management, more advanced economy, more harmonious society, happier life, and better life" during the process of urbanization via the co-effort of government, companies and citizens.

\section{References}

[1] Wu Xibo, Yang Zhaigao, “The Concept of Smart City and Future City Development”, Urban Studies, Vol. 17(2010), pp.56-60.

[2] 2012 White book of smart city, [E-book] Available;Amazon.com.

[3] Information on http://news.sina.com.cn/o/2010-02-04/055017043473s.shtml.

[4] Xu Jing, Chen Xiuwan, "Status quo and existing problems of smart city development in our country”, Science and Technology Management Research,Vol. 7(2014), pp.23-26.

[5] Xu Qingrui, et al, “The Vision, Architecture and Research Models of Smart City”, Journal of Industrial Engineering and Engineering Management, Vol. 4(2012), pp.1-6.

[6] Chen Shanzhi, "Development Strategy of Smart City in China --- from the Perspective of Social and Economic Development and Transition”, Telecommunications Science, Vol. 27(2011) , pp. 1-5.

[7] Feng Maoyan, Jiang Lanzhi, “On the Intelligent City and Intelligent Industry Development 
--- Taking Nanjing City as an Example”, Reformation \& Strategy, Vol.27(2011), pp. 151-155.

[8] Wang Yingluo, System Engineering(3rd. Edt.), Beijing: Higher Education Press(2012).

[9] Gu Jifa, et al, Methodology on WSR Theory, Shanghai:Shanghai Shijie Press(2012).

[10] Chen Dazhang, “System Engineering of the Top Layer Design in Smart City”, Science and Technology Management Research, Vol.1(2014),pp. 16-20. 